\title{
Komposisi Beton Pori Sebagai Bahan Ramah Lingkungan Mengatasi Banjir
}

\author{
Aidil Abrar \\ Program Studi Teknik Sipil, Sekolah Tinggi Teknologi Dumai \\ Jl. Utama Karya Bukit Batrem II \\ aidilabrar@mail-sttdumai.ac.id
}

\begin{abstract}
ABSTRAK
Perubahan iklim yang terjadi mengakibatkan cuaca dapat menjadi semakin panas dan basah. Akibat yang dapat dirasakan langsung oleh manusia adalah dampak dari tingginya cuaca panas yang mengakibatkan kekeringan air, dan dampak lain yang dapat dirasakan yaitu banjir apabila curah hujan yang terjadi terus meningkat. Salah satu inovasi baru dalam pembuatan perkerasan atas tanah yang ramah lingkungan, adalah beton Pori. Beton Pori ini memiliki pori yang lebih besar daripada beton normal dan aspal. Karena Beton Pori ini memiliki banyak pori-pori pada permungkaannya, ini memungkinkan air untuk mengalir dan menghilang secara alami kedalam tanah. Untuk dapat menyimpan air dan mengurangi resiko banjir permukaan. Pori ini dapat dengan cepat mengarahkan kelebihan air jauh dari jalan, permukaan parkir, dan jalan setapak. Tidak seperti beton konvensional, beton ini memiliki rasio kekosongan yang tinggi antara 20\%-35\%. Dengan melakukan eksperimen pada Labor Beton STT Dumai, didapatkan hubungan antara komposisi beton berpori dengan kuat tekan, porositas dan permeabilitas untuk mengetahui kecepatan aliran air yang meresap pada beton. Hal ini memungkinkan resiko banjir permukaan dan kontaminasi aliran air dapat diatasi.
\end{abstract}

Kata kunci: Beton Pori, permeabilitas, porositas dan banjir.

\begin{abstract}
Climate change the weather is getting hotter and wetter. The impact that can be felt directly by humans is the impact of high hot weather which results in water drought, and another impact that can be felt is flooding if the rainfall continues to increase. One of the new innovations in the manufacture of environmentally friendly pavements is Porous concrete. This porous concrete has larger pores than normal concrete and asphalt. Because this Porous Concrete has many pores on its surface, it allows water to flow and naturally dissipate into the soil. To be able to save water and reduce the risk of surface flooding. These pores can quickly direct excess water away from roads, parking surfaces, and walkways. It's that unlike conventional concrete, it has a high void ratio between 20\%-35\%. By conducting experiments on the Concrete Laboratories of STT Dumai, it was found the relationship between the composition of porous concrete with compressive strength, porosity and permeability to determine the speed of water flow that permeated the concrete. This allows the risk of surface flooding and contamination of watercourses to be overcome.
\end{abstract}

Keywords: Porous Concrete, permeability, porosity and flood. 


\section{Pendahuluan}

Kenaikan suhu saat ini dapat merubah iklim sehingga menyebabkan perubahan pola cuaca yang dapat menimbulkan peningkatan maupun penurunan. Dengan perubahan iklim yang terjadi, mengakibatkan cuaca dapat menjadi semakin panas maupun basah. Akibat yang dapat dirasakan langsung oleh manusia adalah dampak dari tingginya cuaca panas yang mengakibatkan kekeringan air, dan dampak lain yang dapat dirasakan yaitu banjir apabila curah hujan yang terjadi terus meningkat. Perubahan-perubahan merugikan tersebut masih ditambah dengan berubahnya siklus udara dan hidrologi yang dipengaruhi oleh hilangnya area resapan air, dan area hijau (Neville, A.M., 2010). Mengingat bahwa pembangunan merupakan aktifitas utama dari setiap Negara dalam rangka meningkatkan kesejahteraan warganya, dapat dikatakan bahwa kerusakan lingkungan sudah merupakan bagian yang tidak dapat dihindarkan dari kegiatan pembangunan(Devrionika et al., 2016).

Fakta akibat perubahan iklim pada saat ini mendorong lahirnya berbagai inovasi produk industri yang terus berkembang dalam dunia arsitektur dan bahan bangunan. Konsep pembangunan arsitektur hijau (Green house) menekankan peningkatan efisiensi dalam penggunaan air, energi, dan material bangunan, mulai dari desain building interior, pembangunan, hingga pemeliharaan bangunan itu ke depan(SK SNI 03-0691-1996, n.d.). Salah satu inovasi baru dalam pembuatan perkerasan atas tanah yang ramah lingkungan, salah satunya adalah Beton Pori. Beton Pori ini memiliki pori yang lebih besar daripada beton normal dan aspal. Karena Beton Pori ini memiliki banyak pori-pori pada permukaannya, memungkinkan air untuk mengalir dan menghilang secara alami kedalam tanah. Untuk dapat menyimpan air dan mengurangi resiko banjir permukaan(Ginting, 2019).

Beton pori atau dapat disebut juga dengan beton berpori. Fungsi dari Beton Pori ini dapat memainkan sebuah aturan mendasar pada sebagian besar desain drainase perkotaan yang berkelanjutan. Menyediakan kemudahan dalam jangka panjang, jawaban dari banjir yang muncul kepermukaan yang dapat diterapkan dengan cepat dan merupakan sebuah solusi baru dari pengeringan dan perkerasan beton dengan cepat dan dengan biaya yang lebih efektif(SK SNI 03-1973-2008, 2015). Beton Pori ini dapat dengan cepat mengarahkan kelebihan air jauh dari jalan, permukaan parkir, dan jalan setapak. Tidak seperti beton konvensional, beton ini memiliki rasio kekosongan yang tinggi antara 20\%-35\%. Hal ini memungkinkan resiko banjir permukaan dan kontaminasi aliran air dapat diatasi(Ginting, 2017).

Beton berpori yang juga dikenal sebagai pervious concrete atau porous concrete merupakan jenis beton yang memiliki pori-pori atau rongga pada strukturnya, sehingga memungkinkan cairan mengalir melalui rongga-rongga yang terdapat pada beton(SK SNI 03-1968-1990, 1990). Menurut ACI 522R-10 Report on Pervious Concrete beton berpori dapat di deskripsikan sebagai beton yang memiliki nilai slump mendekati nol, yang terbentuk dari semen portland, agregat kasar, sedikit agregat halus atau tidak sama sekali, campuran tambahan (admixture), dan air(ACI 522R-10, 2010).

Berdasarkan ACI 522R-10 mix design untuk $1 \mathrm{~m} 3$ pervious concrete terdiri dari semen (270 - $415 \mathrm{~kg})$, agregat (1190 - $1480 \mathrm{~kg})$, faktor air semen $(0,27-0,34)$, dan 
menggunakan chemical admixtures(Amerikan Society For Testing And Materials, 1918).

(Prabowo et al., 2013)melakukan penelitian tentang beton berpori dengan mengurangi proporsi agregat halus pada mix desain beton normal. Agregat batu pecah yang dipakai yaitu ukuran seragam $1-2 \mathrm{~cm}$. Agregat halus dalam pengujiannya dengan proporsi $5 \%, 10 \%$ dan $30 \%$ dari proporsi agregat halus beton normal. Dalam penelitian ini tidak memenuhi spesifikasi sebagai perkerasan untuk badan jalan karena memiliki nilai kuat tekan dan kuat tarik lentur yang rendah, sehingga hanya dapat digunakan sebagai bahan trotoar dan bahu jalan saja(Company, 2015).

\section{Metode Penelitian}

Penelitian yang dilakukan memakai metode kuantitatif dengan melakukan eksperimen di laboratorium Sekolah Tinggi Teknologi (STT) Dumai. Bahan yang digunakan pada penelitian ini terdiri dari: semen, agregat halus (pasir silika) dan agregat kasar (split merak) dengan ukuran 10-20 mm. Faktor air semen (FAS) yang digunakan adalah 0,34. Benda Uji (sampel) penelitian ini untuk uji porositas dan kuat tekan adalah benda uji yang berupa kubus dengan ukuran sampel $15 \mathrm{~cm}$ x 15 $\mathrm{cm} \times 15 \mathrm{~cm}$, dan untuk uji permeabilitas berupa selinder dengan Ø $150 \mathrm{~mm}$ dan tinggi $150 \mathrm{~mm}$. Terdiri dari benda uji dengan perbandingan void rasio dengan persentase $15 \%, 20 \%, 25 \%, 30 \%$, 35\%. Masing-masing variasi terdiri dari 3 sample kubus dan 1 sampel selinder, yang akan di uji pada umur 7, 14, 28, hari sehingga total benda uji sebanyak 20 sampel yang dapat dilihat pada Tabel. 1.

Tabel 1. Benda uji berdasarkan komposisi dan ukuran

\begin{tabular}{ccccc}
\hline Void rasio & Ukuran $(\mathrm{mm})$ & Jenis pengujian & Jumlah sampel & Keterangan \\
\hline $15 \%$ & & 3 & Masing-masing \\
$20 \%$ & $50 \times 50 \times 50$ & Porositas dan & 3 & diuji pada umur \\
$25 \%$ & kuat tekan & 3 & 7,14 ,dan 28 \\
$30 \%$ & & 3 & \\
$35 \%$ & & & 1 & Pengujian umur \\
$15 \%$ & & & 1 & 28 hari \\
$20 \%$ & P: 150, t: 150 & & 1 & \\
$25 \%$ & & 1 & \\
$30 \%$ & & & 20 & \\
$35 \%$ & Jumlah total & & & \\
\hline
\end{tabular}


Unitek : Jurnal Universal Teknologi

Vol.14 No.2 Juli - Desember 2021

e-ISSN : 2580-2582, p-ISSN: 2089-3957

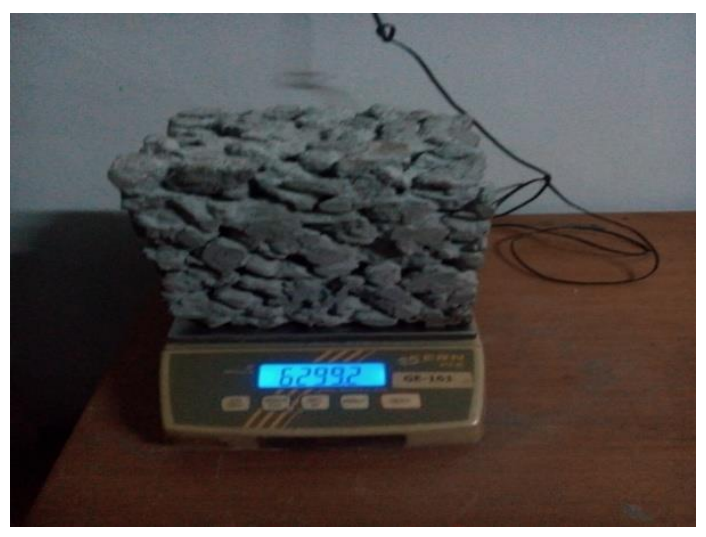

Gambar 1. Benda Uji

\section{Hasil dan Pembahasan}

Hasil pengujian pendahuluan agregat kasar dapat dilihat pada Tabel. 2, pengujian semen pada Tabel. 3, dan pengujian pasir silika pada Tabel. 4 dibawah ini :

Tabel 2. Hasil pengujian agregat kasar

\begin{tabular}{clcc}
\hline No. & Jenis pengujian & Hasil Pengujian & Satuan \\
\hline 1. & Berat jenis (SSD) & 2.65 & - \\
2. & Berat volume & 1.405 & $\mathrm{t} / \mathrm{m}^{3}$ \\
3. & Penyerapan & 2.05 & $\%$ \\
4. & Kadar air & 0.78 & $\%$ \\
5. & Keausan & 6.28 & $\%$ \\
\hline
\end{tabular}

Tabel 3. Hasil pengujian semen type PCC

\begin{tabular}{llcc}
\hline No. & Jenis pengujian & Hasil pengujian & Satuan \\
\hline 1. & Berat jenis (SSD) & 3.14 & - \\
2. & Berat volume & 1.17 & $\mathrm{t} / \mathrm{m}^{3}$ \\
\hline
\end{tabular}

Tabel 4. Hasil pengujian pasir silika

\begin{tabular}{llcl}
\hline No. & Jenis pengujian & Hasil pengujian & Satuan \\
\hline 1. & Berat jenis (SSD) & 2.55 & - \\
2. & Berat volume & 1.201 & $\mathrm{t} / \mathrm{m}^{3}$ \\
\hline
\end{tabular}


Unitek : Jurnal Universal Teknologi

Vol.14 No.2 Juli - Desember 2021

e-ISSN : 2580-2582, p-ISSN: 2089-3957

Pengujian kuat tekan beton mengacu pada SNI 03-1974-1990.

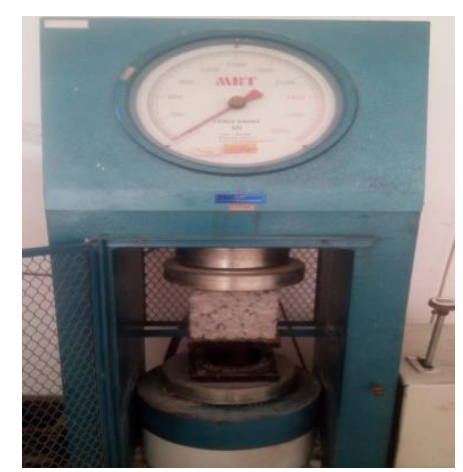

Gambar 2. Pengujian Kuat Tekan

Pengujian porositas untuk mengetahui besarnya prosentase pori-pori beton terhadap volume beton padat.

Dari hasil pengujian dihitung besarnya porositas benda uji dengan persamaan:

Porositas $=\frac{\mathrm{B}-\mathrm{C}}{\mathrm{B}-\mathrm{A}} \cdot 100 \%$

dimana A adalah berat sampel dalam air, W water (gram), B adalah berat sampel kondisi SSD, W saturation (gram), C adalah berat sampel kering oven, W (gram)
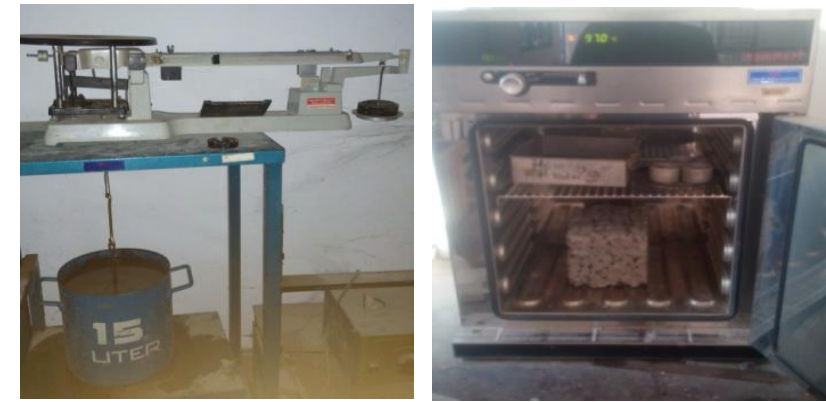

Gambar 3. Pengujian Porositas

Pengujian permeabilitas untuk mengetahui banyaknya air yang mengalir lewat ketebalan beton pada waktu tertentu (seperti disyaratkan pada SK SNI S-36-1990-03 ayat 2.2.1.2). Pengujian ini dilakukan terhadap sampel silinder beton dengan ukuran $\varnothing 15 \mathrm{~cm}$ dan tinggi $15 \mathrm{~cm}$. Tujuan dari pengujian ini adalah untuk mengetahui sejauh mana pengaruh variasi void ratio terhadap permeabilitas beton.
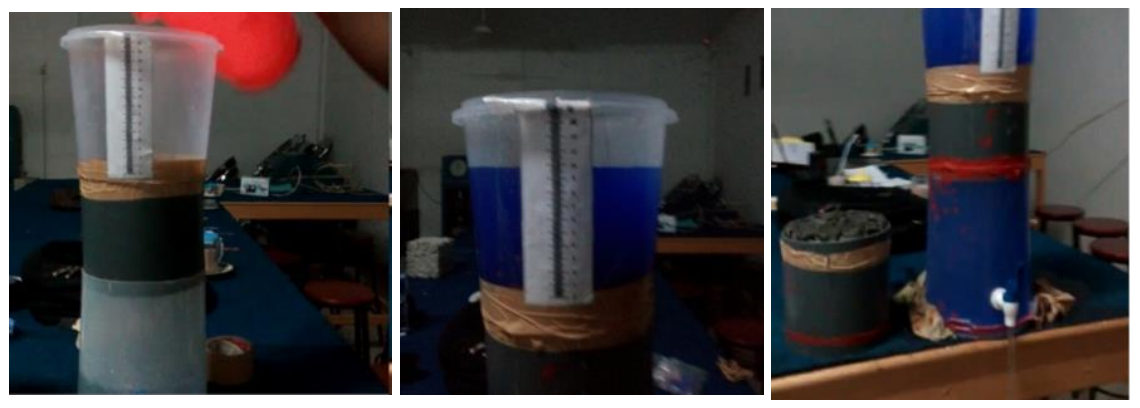

Gambar 4. Pengujian Permeabilitas 
Unitek : Jurnal Universal Teknologi

Vol.14 No.2 Juli - Desember 2021

e-ISSN : 2580-2582, p-ISSN: 2089-3957

\section{Pengujian Kuat Tekan Umur 28 Hari}

Hasil uji kuat tekan umur 28 hari dapat dilihat pada grafik hasil kuat tekan pada Gambar. 5 berikut ini :

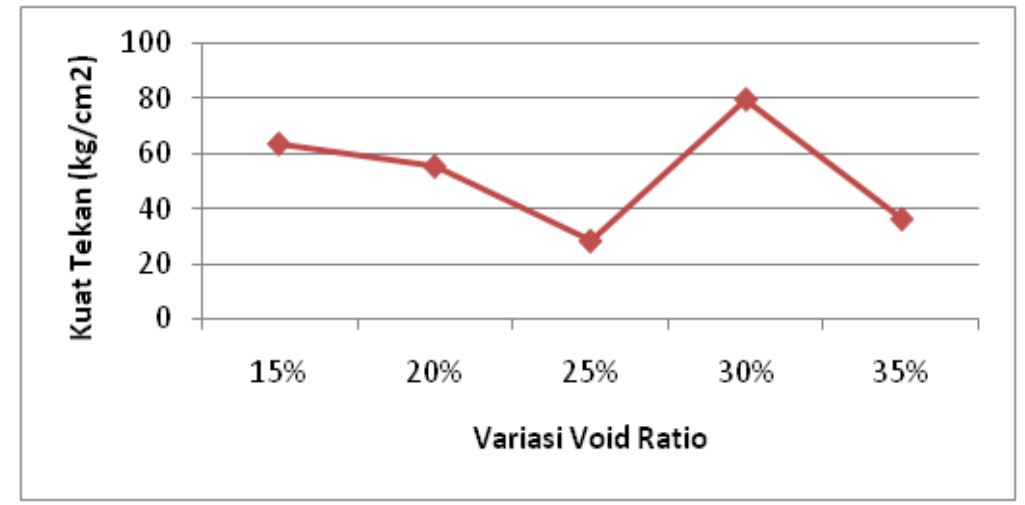

Gambar 5. Kuat tekan beton umur 28 hari

Dari grafik kuat tekan tertinggi pada umur 28 hari berada pada persentase voidratio $30 \%$ dengan kuat tekan sebesar $79.64 \mathrm{~kg} / \mathrm{cm}^{2}$, dan kuat tekan terendah dengan nilai $28.20 \mathrm{~kg} / \mathrm{cm}^{2}$ pada void ratio $25 \%$.

\section{Analisis Pengujian Porositas}

Dari pengujian pada tiap-tiap variasi beton berpori diperoleh nilai porositas dalam Gambar. 6.

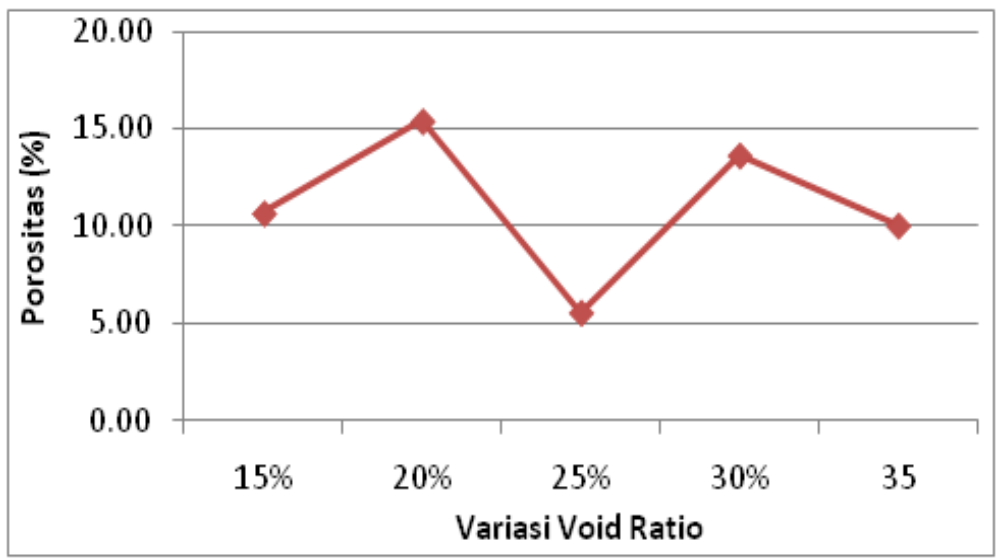

Gambar 6. Grafik hasil uji porositas

\section{Analisis Pengujian Permeabilitas}

Data pengujian permeabilitas disajikan pada Tabel. 5 . 
Unitek : Jurnal Universal Teknologi

Vol.14 No.2 Juli - Desember 2021

e-ISSN : 2580-2582, p-ISSN: 2089-3957

Tabel 5. Hasil pengujian permeabilitas

\begin{tabular}{|c|c|c|c|c|c|c|}
\hline \multirow[t]{2}{*}{ No } & \multirow[t]{2}{*}{ Kode benda Uji } & $\begin{array}{l}\text { Volume } \\
\text { air }\end{array}$ & $\begin{array}{c}\text { Luas } \\
\text { penampang } \\
\text { (A) }\end{array}$ & Waktu & $\begin{array}{c}\text { Kecepatan } \\
\text { alir }\end{array}$ & $\begin{array}{c}\text { Kecepatan } \\
\text { alir rata }\end{array}$ \\
\hline & & (liter) & $(\mathrm{m} 2)$ & (detik) & (l/detik) & (l/detik) \\
\hline \multirow{2}{*}{1.} & \multirow{2}{*}{ TP void ratio $15 \%$} & 2.5 & 0.0177 & 45.85 & 0.055 & \multirow{2}{*}{0.055} \\
\hline & & 2.5 & 0.0177 & 45.76 & 0.055 & \\
\hline \multirow{2}{*}{2.} & \multirow{2}{*}{ TP void ratio $20 \%$} & 2.5 & 0.0177 & 47.25 & 0.053 & \multirow{2}{*}{0.054} \\
\hline & & 2.5 & 0.0177 & 45.09 & 0.055 & \\
\hline \multirow{2}{*}{3.} & \multirow{2}{*}{ TP void ratio $25 \%$} & 2.5 & 0.0177 & 46.17 & 0.054 & \multirow{2}{*}{0.056} \\
\hline & & 2.5 & 0.0177 & 43.33 & 0.058 & \\
\hline \multirow{2}{*}{4.} & \multirow{2}{*}{ TP void ratio $30 \%$} & 2.5 & 0.0177 & 44.19 & 0.057 & \multirow{2}{*}{0.058} \\
\hline & & 2.5 & 0.0177 & 42.66 & 0.059 & \\
\hline \multirow{2}{*}{5.} & \multirow{2}{*}{ TP void ratio $35 \%$} & 2.5 & 0.0177 & 44.28 & 0.056 & \multirow{2}{*}{0.056} \\
\hline & & 2.5 & 0.0177 & 45.67 & 0.055 & \\
\hline
\end{tabular}

Dari data pada Tabel. 5 diperoleh grafik permeabilitas dengan variasi void ratio yang digambarkan pada Gambar. 7 di bawah ini:

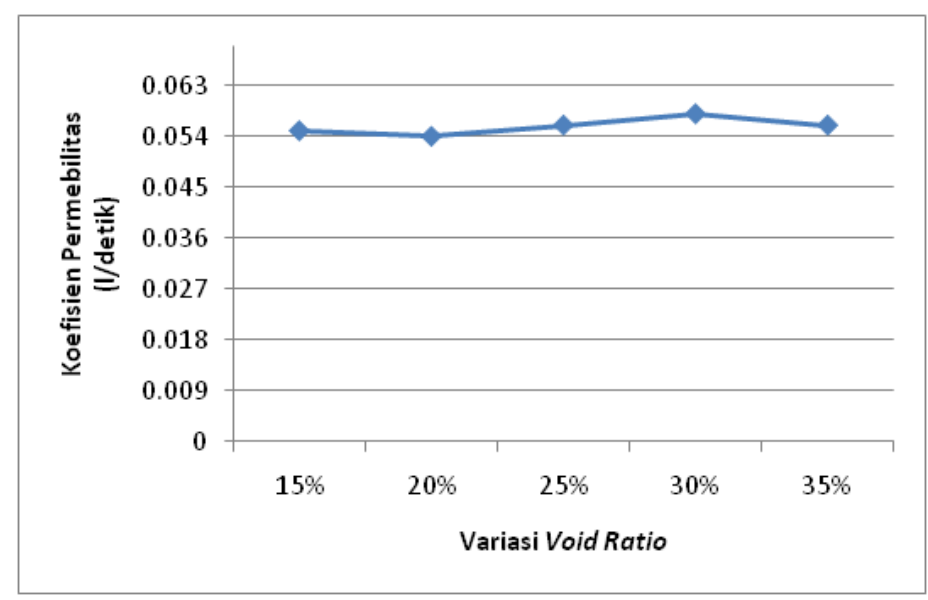

Gambar 7. Grafik hasil uji permeabilitas

Dari pengujian yang dilakukan di peroleh hasil permeabilitas yang baik pada angka pori (void ratio) 30\% dengan kecepatan aliran $0.058 \mathrm{l} / \mathrm{dt} / \mathrm{m}^{2}$.

\section{Analisis Hasil Pengujian dengan Metode Analisis Regresi}

Analisis regresi yang digunakan adalah analisis regresi polinomial orde 2 . Pembuatan regresi non linier ini bermaksud untuk mengetahui nilai koefisien determinasi (R) yang menunjukkan seberapa besar kecocokan ketetapan garis regresi yang terbentuk dan mengetahui sejauh mana hubungan antara variabelvariabel penyusunnya. 


\section{Pengujian Porositas}

Hubungan antara nilai porositas dengan variasi void ratio disajikan dalam Gambar 8 di bawah ini.

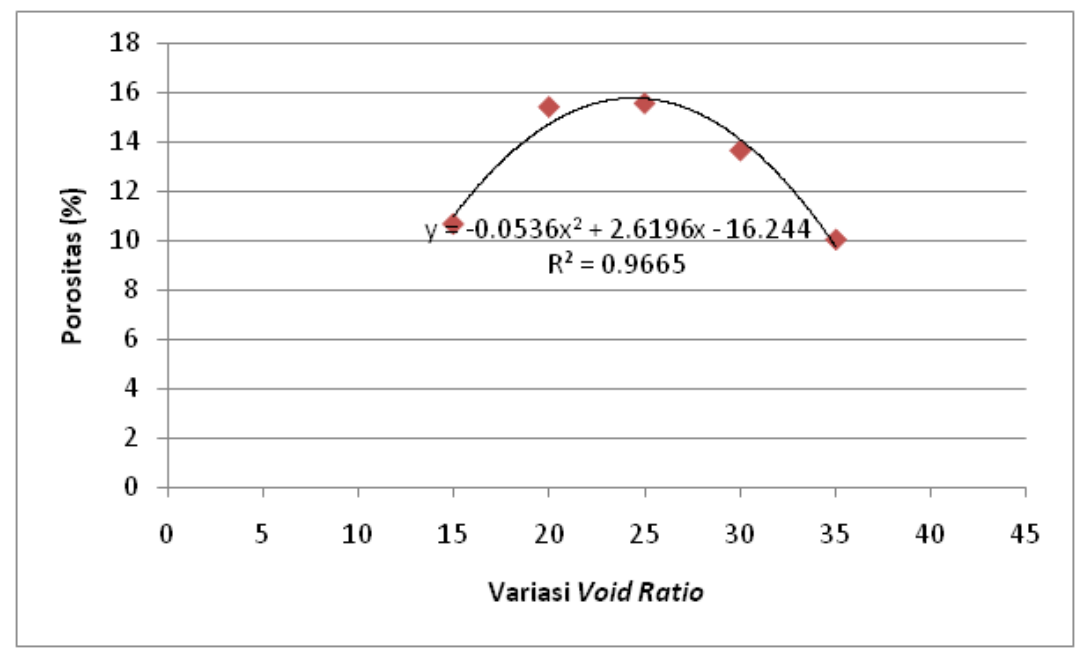

Gambar 8. Grafik nilai porositas

Perhitungan besarnya persen void ratio yang optimum untuk menghasilkan nilai porositas beton Pori yang minimum adalah sebagai berikut:

$P=-0.053(V R)^{2}+2.619(V R)-16.24$

Dengan,

$\mathrm{P}=$ porositas beton $(\%)$

VR $=$ kadar void ratio $(\%)$

$\mathrm{P}$ minimum terjadi pada $\mathrm{dP} / \mathrm{d}(\mathrm{VR})=0$

Maka dP/d(VR) $=-0.106(V R)+2.619$

Dari persamaan di atas diperoleh nilai VR dan P sebagai berikut:

$\mathrm{VR}=\frac{2.619}{0.106}$

$\mathrm{VR}=24.71$

Dengan memasukkan nilai VR ke persamaan awal maka diperoleh:

$P=-0.053(24.71)^{2}+2.619(24.71)-16.24$

$P=16.114$

Dari hasil perhitungan di atas diambil nilai VR $=24.71$ yang berarti variasi void ratio yang optimum adalah sebesar $24.71 \%$ yang akan menghasilkan nilai porositas beton minimum $(\mathrm{P})$ sebesar 16,114\%.

\section{Pengujian Permeabilitas}

Hubungan antara nilai koefisien permeabilitas dengan variasi void ratio dalam Gambar 9 di bawah ini. 


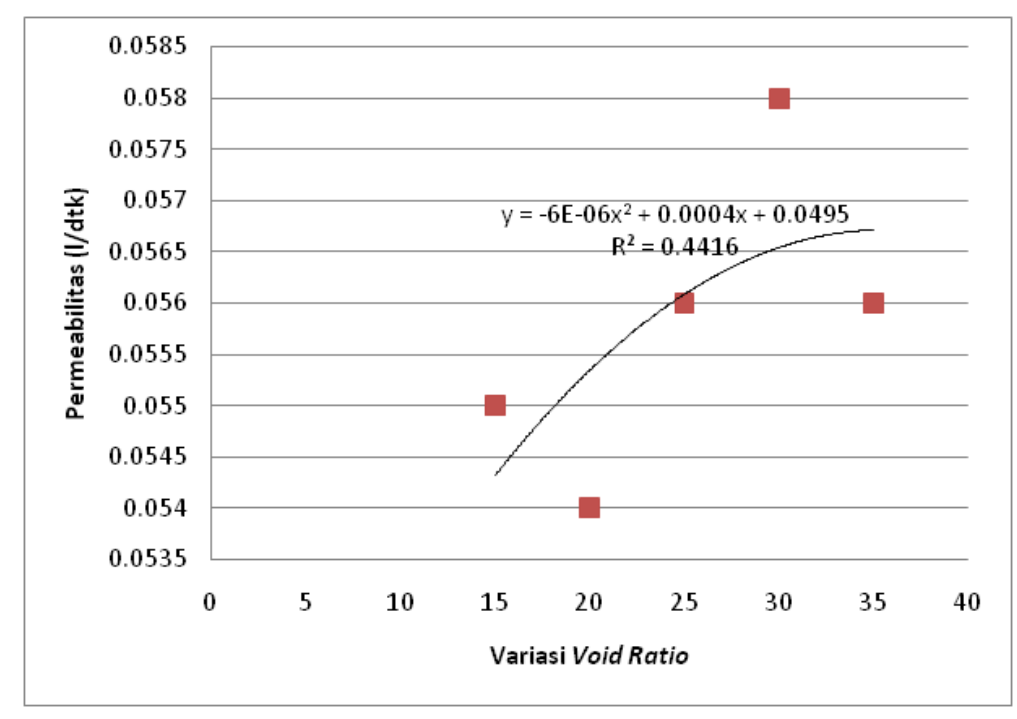

Gambar 9. Grafik permeabilitas

$k=-0.000006(V R)^{2}+0.0004(V R)+0,0495$

Dengan,

$\mathrm{k}=$ permeabilitas beton (\%)

$\mathrm{VR}=$ variasi void ratio $(\%)$

$\mathrm{P}$ minimum terjadi pada $\mathrm{dk} / \mathrm{d}(\mathrm{VR})=0$

Maka dP/d(VR) $=-0.0000012(V R)+0.0004$

Dari persamaan di atas diperoleh nilai VR dan k sebagai berikut:

$\mathrm{VR}=\frac{0.0004}{0.000012}$

$\mathrm{VR}=33.33$

Dengan memasukkan nilai VR ke persamaan awal maka diperoleh:

$k=-0.000006(33.33)^{2}+0.0004(33.33)+0,0495$

$k=0,0561$

Dari hasil perhitungan di atas diambil nilai VR $=33,33$ yang berarti variasi void ratio yang optimum adalah sebesar $33,33 \%$ yang akan menghasilkan nilai permeabilitas beton minimum (k) sebesar 0,0561 l/detik.

\section{Simpulan}

Dari pengujian yang dilakukan dapat ditarik kesimpulan untuk Beton Pori ini didapatkan hasil bahwa semakin meningkat nilai angka pori semakin naik nilai porositas dan permeabilitasnya yaitu pada komposisi angka pori $10 \%, 20 \%$ dan $25 \%$. Pada komposisi 30\% dan 35\% nilai porositas mulai menurun sehingga nilai optimum kuat tekan beton dan nilai permeabilitas yang baik hasilnya pada angka pori (void ratio) $30 \%$. Dengan hasil nilai kuat tekan $97.65 \mathrm{~kg} / \mathrm{cm}^{2}$, nilai porositas $13.65 \%$ dan debit aliran $0.058 \mathrm{l} / \mathrm{dt} / \mathrm{m}^{2}$. 


\section{Daftar Pustaka}

ACI 522R-10, I. (2010). Report on Berpori Concrete. USA: Concrete Institute Committee 522.

Amerikan Society For Testing And Materials. (1918). Concrete and Material Aggregates (Including Manual of Agregat and Concrete Testing). ASTM. Philadelphia.

Company, T. arc. (2015). Permeable Concrete Solution Guide version November 2015. Tarmac Portland House,Birmingham.

Devrionika, D., Abrar, A., \& Putra, S. A. (2016). Prosiding Seminar ACE. Analisis Pemanfaatan Limbah Besi Pengganti Agregat Kasar Pada Beton Sebagai Bahan Inovasi Mengatasi Air Permukaan, 8(15), 17-28.

Ginting, A. (2017). Pengaruh Rasio Agregat Semen Dan Faktor Air Semen Terhadap. Jurnal Teknik, 5(April 2015), 1-85.

Ginting, A. (2019). Kuat Tekan dan Porositas Beton Porous dengan Bahan Pengisi Styrofoam. Jurnal Teknik Sipil, $11(2), \quad$ 76-98. https://doi.org/10.28932/jts.v11i2.1404

Neville, A.M., B. (2010). , Properties of Concrete, Fourth Edition, Pearson Education Limited. Essex, England.

Prabowo, D. A., Setyawan, A., \& Sambowo, K. A. (2013). Desain Beton Berpori Untuk Perkerasan Jalan Yang Ramah Lingkungan. E-Jurnal MATRIKS TEKNIK SIPIL, 8(2), 137750.

SK SNI 03-0691-1996, 1996. (n.d.). Bata Beton (Paving Block). Jakarta: Badan Standarisasi Nasional.

SK SNI 03-1968-1990, I. (1990). Metode Pengujian Analisis Saringan Agregat Halus dan Kasar. Jakarta: Badan Standarisasi Nasional.

SK SNI 03-1973-2008, 2008. (2015). Cara Uji Berat Isi, Volume Produksi Campuran dan Kadar Udara Beton. Jakarta: Badan Standarisasi Nasional. 